\title{
Enhanced cognitive behaviour therapy for adolescents with eating disorders: A systematic review of current status and future perspectives
}

\author{
Riccardo Dalle Grave, MD¹, Maddalena Conti, PsyD¹, Massimiliano Sartirana, PsyD², \\ Selvaggia Sermattei, $\mathrm{PsyD}^{3}$, Simona Calugi, $\mathrm{PhD}^{1}$ \\ ${ }_{1}^{1}$ Department of Eating and Weight Disorders, Villa Garda Hospital, Via Monte Baldo 89, 37016 Garda (VR), Italy. \\ ${ }^{2}$ Associazione Disturbi Alimentari (ADA), Via Sansovino,16, 37139, Verona \\ ${ }^{3}$ Anoressia, Bulimia, Obesità (ABO), Via Pievano Rolando, 50053 Empoli (FI)
}

\section{Keywords}

Anorexia nervosa

Outpatient treatment

Inpatient treatment

Cognitive behavioural therapy

Treatment outcomes

Adolescents

\begin{abstract}
This systematic review analysed published data on the effectiveness of enhanced cognitive behaviour therapy (CBT-E) for adolescents with eating disorders. Of the 28 papers retrieved, eight (6 case series, 1 prospective cohort study, and 1 nonrandomized effectiveness trial) met the inclusion criteria and revealed the following five findings. First, outpatient CBT-E is well accepted by adolescent patients with anorexia nervosa; it is completed by about two-thirds of participants, and produces improvements in eating-disorder and general psychopathology. Remission from anorexia nervosa is achieved by about $50 \%$ of patients at 12 -month follow-up. Second, outpatient CBT-E seems more effective for adolescents than adults. Third, inpatient CBT-E for adolescents with anorexia nervosa seems particularly effective - about $80 \%$ of patients achieve normal weight by 12 -month follow-up. Fourth, CBT-E also seems promising for adolescents who are not underweight. Fifth, CBT-E appears to yield similar outcomes to FBT in terms of weight regain and eating-disorder and general psychopathology improvements at 6- and 12-month follow-up. The fourth and fifth findings derive from a single study and require confirmation. In conclusion, CBT-E is a viable and promising treatment for adolescents with eating disorders.
\end{abstract}

\section{Introduction}

Eating disorders have a marked negative effect on the physical health and psychosocial functioning of adolescents and their families (American Psychiatric Association, 2013). They are strongly associated with other mental disorders, role impairment, and suicidality (Swanson, Crow, Le Grange, Swendsen, \& Merikangas, 2011). Therefore, they must be treated early and effectively (Flynn et al., 2020) to prevent long-lasting adverse, sometimes devastating, effects (Wonderlich, Bulik, Schmidt, Steiger, \& Hoek, 2020).
The outcomes of eating disorder treatments for adolescents remain modest, although some promising treatments for this population have emerged. A specific form of family therapy, termed 'Family-Based Treatment' (FBT) (Lock \& Le Grange, 2013), also known as the 'Maudsley method/ Maudsley approach', has been evaluated in several randomized control trials (RCTs) on patients with anorexia nervosa (Le Grange et al., 2016; Lock et al., 2010) and bulimia nervosa (Le Grange, Crosby, Rathouz, \& Leventhal, 2007; Le Grange, Lock, Agras, Bryson, \& Jo, 2015). The outcome data from these trials indicate that less than $40 \%$ of adolescen-

Copyright @ 2021 Riccardo Dalle Grave. This is an open-access article distributed under the terms of the Creative Commons Attribution License (CC $\mathrm{BY})$. The use, distribution or reproduction in other forums is permitted, provided the original author(s) and the copyright owner(s) are credited and that the original publication in this journal is cited, in accordance with accepted academic practice. No use, distribution or reproduction is permitted which does not comply with these terms.

Riccardo Dalle Grave (₫) rdalleg@gmail.com

Received: 10 January 2021; Accepted: 25 January 2021; Published online: 03 February 2021. doi: 10.32044/ijedo.2021.01 
ts with anorexia nervosa and less than $50 \%$ of those with bulimia nervosa treated via FBT achieve remission (Dalle Grave, Eckhardt, Calugi, \& Le Grange, 2019). Moreover, when it comes to its clinical application, FBT is labour-intensive and unacceptable to some families and patients, because it requires parents to participate in sessions and control their child's eating. These data indicate the need to find alternative treatment approaches (Lock, 2011).

According to the most recent guidelines by the National Institute for Health and Clinical Excellence (NICE), enhanced cognitive behaviour therapy (CBT-E) for adolescents is considered the most valid alternative to FBT, and has been recommended for children or young people with anorexia nervosa or bulimia nervosa when FBT is unacceptable, contraindicated, or ineffective (National Guideline Alliance, 2017). This recommendation has been based on the promising results obtained by some recent case series that assessed the effectiveness of CBT-E in adolescents with anorexia nervosa (Calugi, Dalle Grave, Sartirana, \& Fairburn, 2015; Dalle Grave, Calugi, Doll, \& Fairburn, 2013) and not-underweight eating disorders (Dalle Grave, Calugi, Sartirana, \& Fairburn, 2015).

CBT-E for adolescents has been described in detail in a dedicated manual (Dalle Grave \& Calugi, 2020). In brief, CBT-E is a collaborative individual psychological treatment that addresses in a flexible and personalized way the eating-disorder psychopathology operating in the individual patient, rather than that specific to a particular DSM-5 eating disorder diagnosis (Dalle Grave, Sartirana, Sermattei, \& Calugi, 2020). The treatment never uses 'prescriptive' or 'coercive' procedures, and never asks the young person to do anything that they do not agree to do. Patients are always actively involved in all phases of CBT-E, from the decision to start treatment to the strategies used to address weight regain, dietary restraint, the overvaluation of shape and weight, and other features of their eating disorder. The treatment is delivered in three steps. Step One gives patients the opportunity to think afresh about their eating problem and the processes maintaining it. This is followed by a detailed analysis of the pros and cons of tackling their eating disorder, including weight regain, if indicated. If patients do not conclude that they have a problem to address, the treatment is interrupted, but this is it a rare occurrence. Step Two has the goal of helping patients regain weight and address their individual eating-disorder psychopathology (overvaluation of shape, weight and eating control, dietary restraint and restriction, binge-eating and purging episodes, excessive exercising) and the processes maintaining it. Step Three has the aim of bringing treatment to a conclusion and enabling patients to develop specific skills for preventing relapse.

In underweight patients, the treatment involves 40 sessions over 9-12 months, while in those who are not underweight the treatment is delivered in 20 outpatient sessions over 6 months. Treatment will also include one session with the parents alone, and several brief sessions with the patient and parents together immediately after individual sessions. These sessions aim to help the parents to create a home environment conducive to the patient's attempts to change. However, the nature and extent of parental assistance is always agreed to by the patient and therapist beforehand.

CBT-E has been also adapted for delivery in intensive settings of care, such as day-hospital and inpatient units (Dalle Grave, 2012; Dalle Grave, Bohn, Hawker, \& Fairburn, 2008). Inpatient CBT-E maintains all of the main strategies and procedures of CBT-E, which are delivered in both individual sessions and a group format. Rather than a single therapist, the treatment is delivered by a multidisciplinary team comprising physicians, psychologists, dietitians, and nurses, all fully trained in CBT-E. Assistance with eating is provided in the first weeks of inpatient treatment to help patients get over their difficulties in real time.

A unified treatment like CBT-E, which has been designed to treat all the eating-disorder diagnostic categories in both adults and adolescents across the spectrum of care (Dalle Grave, Sartirana, et al., 2020), could potentially overcome several of the problems encountered by fragmented clinical services, which offer conceptually different treatments for adolescents and adults in different care settings. Without a unified approach, which is the case in the vast majority of clinical services, patients and their families are often obliged to change the nature of treatment when the adolescent is moved to an adult service on reaching their age of majority or an inpatient treatment when indicated. Such radical changes in the nature of the treatment may disrupt care pathways and confuse patients as to the strategies and procedures they should adopt to overcome their eating disorder. In contrast, a unified treatment like CBT-E has the potential to help patients to be moved seamlessly from adolescent to adult services and through different levels of care without changing the nature of the treatment itself (Dalle Grave, Sartirana, et al., 2020).

After the NICE guidelines recommended CBT-E for adolescents with anorexia nervosa, several studies assessing the effectiveness of this treatment have been published. However, the published literature on this topic has not yet undergone systematic review and we, therefore, set out to conduct one. 
The literature was assessed in accordance with the PICO process (Richardson, Wilson, Nishikawa, \& Hayward, 1995) (as far as we know for the first time) as follows: P, population-female and male adolescents who met the DSM-5 diagnostic criteria for eating disorder (anorexia nervosa, bulimia nervosa, binge-eating disorder or other specified and unspecified eating disorder) and had an age range or mean age of between 10 and 19 years at baseline; I, intervention-CBT-E for eating disorders; C, comparison-before and after treatment and follow-ups; $\mathrm{O}$, outcome-change in body weight and eating-disorder and general psychopathology, however expressed.

\section{Methods}

The review was conducted in conformity to the Preferred Reporting Items for Systematic Review and Meta-Analyses (PRISMA) guidelines (Liberati et al., 2009).

\section{Inclusion and Exclusion Criteria}

All studies evaluating CBT-E in adolescents with eating disorders were included if they met the following criteria: (i) papers written in English reporting human data; (ii) the sample met standard criteria for the definition of anorexia nervosa, bulimia nervosa, binge-eating disorder or other specified and unspecified eating disorder; (iii) original articles on studies with longitudinal design; and (iv) prospective observational, experimental, or quasi-experimental controlled or non-controlled studies documenting CBT-E outcome in adolescent patients with anorexia nervosa, bulimia nervosa, binge-eating disorder or other specified and underspecified eating disorder. The following criteria were grounds for exclusion: (i) reviews or non-original articles (i.e., case reports, editorials, Letters to the Editor, or book chapters); and (ii) cross-sectional studies.

\section{Information Source and Search Strategy}

The literature search was designed and performed independently in duplicate by two authors. The PubMed database was systematically screened using the following MeSH terms: ("anorexia nervosa" [MeSH Terms] OR ("anorexia" [All Fields] AND "nervosa"[All Fields]) OR "anorexia nervosa"[All Fields] OR ("bulimia nervosa"[MeSH Terms] OR ("bulimia"[All Fields] AND "nervosa"[All Fields]) OR "bulimia nervosa"[All Fields] OR "underweight"[All Fields] OR "not underweight" [All Fields] OR "binge-eating disorder" [MeSH Terms] OR "binge-eating disorder" [MeSH Terms] OR "binge-eating disorder" [All Fields] OR "binge-eating disorder"[All Fields])) AND ("adolescences"[All Fields] OR "adolescence"[All Fields] OR "adolescent" [MeSH Terms] OR "adolescent"[All Fields] OR "adolescence" [All Fields] OR "adolescents" [All Fields] OR “adolescents"[All Fields] OR "young people"[All Fields]) AND "enhanced" [All Fields] AND ("cognitive behaviour therapy" [All Fields] OR "cognitive behavioral therapy" [MeSH Terms] OR "cognitive behavioral therapy"[All Fields] OR "cognitive behavior therapy"[All Fields]) AND ("outcome"[All Fields] OR “outcomes"[All Fields]).

In addition, a manual free text search of the above terms was also carried out to retrieve other articles that had not been identified via the initial search strategy, and the references lists of all articles were carefully checked to ensure that all relevant studies had been identified. Publication date was not considered an exclusion criterion for the purposes of this review.

\section{Data Collection Process and Data Items}

First, the two authors carried out independent assessments of the title and abstract of each paper for the suitability of language and relevance of subject matter. The papers selected in this manner were then examined for their appropriateness for inclusion and method quality. The first author, year of publication, study design, sample size and setting, age, baseline body mass index (BMI)-for-age percentile, presence of follow-up and maximum duration of follow-up, end of treatment outcome and follow-up outcome of each are reported in Table 1.

\section{Study Selection}

The National Institute for Health and Care Excellence (NICE) guidelines checklist was used for quality appraisal of studies (National Institute for Health and Clinical Excellence), in which a total score of $0-3$ indicates poor quality; between 4 and 6 fair quality; and $\geq 7$ good quality.

\section{Data Synthesis}

Due to the lack of RCTs among the resulting studies, a meta-analysis could not be performed. Therefore, all studies that met the inclusion criteria have been presented in a narrative synthesis (Popay et al., 2005).

\section{Results}

The initial search retrieved 28 papers. After screening, seven papers were excluded for being an inappropriate type of article (i.e., reviews, case reports). Moreover, eight papers 
Table 1. Studies included in the systematic review

\begin{tabular}{|c|c|c|c|c|c|c|c|}
\hline \begin{tabular}{|l} 
First \\
author \\
(year)
\end{tabular} & \begin{tabular}{|l} 
Study \\
design
\end{tabular} & Sample & Age & \begin{tabular}{|l} 
Baseline \\
BMI-for-age \\
percentile
\end{tabular} & Follow-up & $\begin{array}{l}\text { End of treatment } \\
\text { outcome }\end{array}$ & $\begin{array}{l}\text { Last follow-up } \\
\text { outcome }\end{array}$ \\
\hline $\begin{array}{l}\text { Dalle Grave } \\
(2013)\end{array}$ & Case series & $\begin{array}{l}\mathrm{n}=46 \\
\text { outpatients; } \\
\mathrm{n}=29 \\
\text { completers }\end{array}$ & $\begin{array}{l}\text { Mean }=15.5 \\
\text { years }(S D=1.3, \\
\text { range 13-17 } \\
\text { years) }\end{array}$ & $\begin{array}{l}\text { Mean=2.86 } \\
(\mathrm{SD}=3.35)\end{array}$ & $\begin{array}{l}\text { Yes, } 60 \\
\text { weeks } \\
(\mathrm{n}=29)\end{array}$ & $\begin{array}{l}\text { Mean BMl-for-age } \\
\text { percentile } 30.3 \\
\text { (SD=16.7) } \\
96.6 \% \text { of completers } \\
\text { had minimal residual } \\
\text { eating-disorder } \\
\text { psychopathology* }\end{array}$ & \begin{tabular}{|l|} 
Mean BMI-for-age \\
percentile 35.1 (26.0) \\
$89.7 \%$ of completers \\
had minimal residual \\
eating-disorder \\
psychopathology*
\end{tabular} \\
\hline $\begin{array}{l}\text { Dalle Grave } \\
\text { (2014) }\end{array}$ & Case series & $\begin{array}{l}n=27 \text { inpatients; } \\
n=26 \\
\text { completers }\end{array}$ & $\begin{array}{l}\text { Mean }=16 \text { years } \\
(\mathrm{SD}=1.1 \text {, range } \\
13-17 \text { years) }\end{array}$ & $\begin{array}{l}\text { Mean=2.7 } \\
(\mathrm{SD}=4.3)\end{array}$ & $\begin{array}{l}\text { Yes, } 6 \\
\text { months } \\
(n=22) \text { and } \\
12 \text { months } \\
(n=23)\end{array}$ & $\begin{array}{l}\text { Mean BMI-for-age } \\
\text { percentile } 35.5 \\
\text { (SD=14.5) } \\
96.2 \% \text { achieved } \\
\text { a BMI centile } \\
\text { corresponding to } \\
\text { BMI } 18.5 \\
38.5 \% \text { of completers } \\
\text { had minimal residual } \\
\text { eating disorder } \\
\text { psychopathology }\end{array}$ & $\begin{array}{l}\text { Mean BMI-for-age } \\
\text { percentile } 29.5 \\
\text { (SD=19.6) } \\
82.6 \% \text { had a BMl } \\
\text { centile corresponding } \\
\text { to BMl } 18.5 \\
60.9 \% \text { of completers } \\
\text { had minimal residual } \\
\text { eating-disorder } \\
\text { psychopathology** }\end{array}$ \\
\hline $\begin{array}{l}\text { Dalle Grave } \\
(2015)\end{array}$ & Case series & $\begin{array}{l}n=68 \\
\text { outpatients; } \\
n=51 \\
\text { completers }\end{array}$ & $\begin{array}{l}\text { Mean }=16.5 \\
\text { years }(S D=1.7, \\
\text { range 13-19 } \\
\text { years) }\end{array}$ & $\begin{array}{l}\text { Mean=42.9 } \\
(\mathrm{SD}=23.2)\end{array}$ & No & $\begin{array}{l}\text { Mean BMl-for-age } \\
\text { percentile } 44.1 \\
\text { (SD=20.7) } \\
\text { 82.4\% of completers } \\
\text { had minimal residual } \\
\text { eating-disorder } \\
\text { psychopathology }\end{array}$ & --- \\
\hline $\begin{array}{l}\text { Calugi } \\
(2015)\end{array}$ & $\begin{array}{l}\text { Prospective } \\
\text { cohort study }\end{array}$ & $\begin{array}{l}\text { Adolescents: } \\
n=46 \\
\text { outpatients; } \\
n=29 \\
\text { completers } \\
\\
\text { Adults: } \\
n=49 \\
\text { outpatients; } \\
n=32 \\
\text { completers }\end{array}$ & $\begin{array}{l}\text { Adolescents: } \\
\text { Mean=15.5 } \\
(\mathrm{SD}=1.3) \\
\\
\text { Adults: } \\
\text { Mean=24.6 } \\
(\mathrm{SD}=5.2)\end{array}$ & $\begin{array}{l}\text { Adolescents: } \\
\text { Mean=2.86 } \\
(\mathrm{SD}=3.35) \\
\\
\text { Adults: } \\
\text { Mean } \mathrm{BMl}=17.7 \\
(\mathrm{SD}=1.4)\end{array}$ & No & & --- \\
\hline $\begin{array}{l}\text { Calugi } \\
(2019)\end{array}$ & Case series & $\begin{array}{l}\mathrm{n}=62 \text { inpatients; } \\
\mathrm{n}=56 \\
\text { completers }\end{array}$ & $\begin{array}{l}\text { Mean }=16.4 \\
\text { years } \\
\text { (SD=1.2, range } \\
13-18 \text { years) }\end{array}$ & $\begin{array}{l}\text { Mean=1.8 } \\
(\mathrm{SD}=3.5)\end{array}$ & $\begin{array}{l}\text { Yes, } 6 \\
\text { months } \\
(n=47) \text { and } \\
12 \text { months } \\
(n=46)\end{array}$ & $\begin{array}{l}\text { Mean BMl-for-age } \\
\text { percentile } 33.04 \\
96.4 \% \text { reached } \\
\text { a BMI-for-age } \\
\text { percentile } \\
\text { corresponding to the } \\
\text { normal weight cut-off } \\
\text { (i.e., BMl 18.5) at } \\
\text { age 18 } \\
\text { All psychological } \\
\text { outcome measures } \\
\text { significantly } \\
\text { decreased }\end{array}$ & $\begin{array}{l}\text { Mean BMI-for-age } \\
\text { percentile } 29.44 \\
80.4 \% \text { reached } \\
\text { a BMI-for-age } \\
\text { percentile } \\
\text { corresponding to the } \\
\text { normal weight cut-off } \\
\text { (i.e., 18.5) at age } 18 \\
\text { All psychological } \\
\text { outcome measures } \\
\text { significantly } \\
\text { decreased }\end{array}$ \\
\hline $\begin{array}{l}\text { Dalle Grave } \\
(2019)\end{array}$ & Case series & $\begin{array}{l}n=49 \\
\text { outpatients; } \\
n=35 \\
\text { completers }\end{array}$ & $\begin{array}{l}\text { Mean=15.5 } \\
\text { years } \\
(\mathrm{SD}=1.7, \text { range } \\
11-18 \text { years })\end{array}$ & $\begin{array}{l}\text { Mean=5.67 } \\
(\mathrm{SD}=7.30)\end{array}$ & $\begin{array}{l}\text { Yes, } 20 \\
\text { weeks } \\
(\mathrm{n}=29)\end{array}$ & $\begin{array}{l}\text { Mean BMI-for-age } \\
\text { percentile } 32.3 \\
\text { (SD=4.6) ITT analysis } \\
\text { Significant } \\
\text { improvement in } \\
\text { eating-disorder } \\
\text { and general } \\
\text { psychopathology }\end{array}$ & $\begin{array}{l}\text { Mean BMI-for-age } \\
\text { percentile } 30.5 \\
\text { (SD=2.6) ITT analysis } \\
\text { Significant } \\
\text { improvement in } \\
\text { eating-disorder } \\
\text { and general } \\
\text { psychopathology }\end{array}$ \\
\hline
\end{tabular}


Table 1. continue

\begin{tabular}{|c|c|c|c|c|c|c|c|}
\hline \begin{tabular}{|l}
$\begin{array}{l}\text { First } \\
\text { author } \\
\text { (year) }\end{array}$ \\
\end{tabular} & \begin{tabular}{|l|} 
Study \\
design
\end{tabular} & Sample & Age & $\begin{array}{l}\text { Baseline } \\
\text { BMI-for-age } \\
\text { percentile }\end{array}$ & Follow-up & $\begin{array}{l}\text { End of treatment } \\
\text { outcome }\end{array}$ & $\begin{array}{l}\text { Last follow-up } \\
\text { outcome }\end{array}$ \\
\hline $\begin{array}{l}\text { Ile Grave } \\
\text { 20) }\end{array}$ & Case series & $\begin{array}{l}\text { Adolescents: } \\
\mathrm{n}=74 \text { inpatients; } \\
\mathrm{n}=63 \\
\text { completers } \\
\text { Adults: } \\
\mathrm{n}=81 \text { inpatients; } \\
\mathrm{n}=71 \text { completers }\end{array}$ & $\begin{array}{l}\text { Adolescents: } \\
\text { Mean=16.5 } \\
\text { years } \\
\text { (SD=1.4, range } \\
13-19 \text { years) } \\
\text { Adults: } \\
\text { Mean=16.5 } \\
\text { years } \\
\text { ( } S D=1.4 \text {, range } \\
13-19 \text { years) }\end{array}$ & $\begin{array}{l}\text { Adolescents: } \\
\text { Mean=1.4 } \\
\text { (SD=3.2) } \\
\text { Adults: } \\
\text { Mean BMI }=15.1 \\
(\mathrm{SD}=2.3)\end{array}$ & $\begin{array}{l}\text { Yes, } 20 \text { and } \\
60 \text { weeks } \\
20 \text { weeks: } \\
\text { adolescents } \\
n=46 ; \text { adults } \\
n=53 \\
\\
60 \text { weeks: } \\
\text { adolescents } \\
n=45 ; \text { adults } \\
n=36\end{array}$ & $\begin{array}{l}\text { Adolescents: Mean } \\
\text { BMI-for-age percentile } \\
32.1 \text { (SE=2.0) ITT } \\
\text { analysis } \\
\mathrm{n}=48 \text { (76.2\%) } \\
\text { displayed full } \\
\text { response } \\
\\
\text { Adults: } \\
\text { Mean BMI } 19.9 \\
\text { (SE=0.1) ITT analysis } \\
\mathrm{n}=50 \text { (70.4\%) } \\
\text { displayed full } \\
\text { response }\end{array}$ & $\begin{array}{l}\text { Adolescents: Mean } \\
\text { BMI-for-age percentile } \\
23.2 \text { (SD=4.4) ITT } \\
\text { analysis } \\
\mathrm{n}=22 \text { (48.9\%) } \\
\text { displayed full } \\
\text { response } \\
\\
\text { Adults: } \\
\text { Mean BMI } 18.6 \\
\text { (SE=0.3) ITT analysis } \\
\mathrm{n}=20 \text { (55.6\%) } \\
\text { displayed full } \\
\text { response }\end{array}$ \\
\hline $\begin{array}{l}\text { Le Grange } \\
(2020)\end{array}$ & \begin{tabular}{|l|} 
Non- \\
randomized \\
effectiveness \\
trial
\end{tabular} & $\begin{array}{l}\text { CBT-E: } \\
n=46 \\
\text { outpatients; } \\
n=29 \\
\text { completers } \\
\\
\text { FBT: } \\
n=51 \\
\text { outpatients; } \\
n=33 \\
\text { completers }\end{array}$ & $\begin{array}{l}\text { Mean }=14.6 \\
\text { years } \\
(S D=1.8, \text { range } \\
11-19)\end{array}$ & $\begin{array}{l}\text { CBT-E lower } \\
\text { weight: } \\
\% \text { median } \\
\text { BMI=3.50 } \\
\text { CBT-E higher } \\
\text { weight: \% } \\
\text { median } \\
\text { BMl=11.72 } \\
\text { FBT lower } \\
\text { weight: } \\
\% \text { median } \\
\text { BMl=3.97 } \\
\text { FBT higher } \\
\text { weight: \% } \\
\text { median } \\
\text { BMl=12.09 }\end{array}$ & $\begin{array}{l}\text { Yes, } 6 \text { and } \\
12 \text { months } \\
\\
6 \text { months: } \\
\text { CBT-E } \\
n=22 ; \text { FBT } \\
n=20 \\
\\
12 \text { months: } \\
\text { CBT-E } \\
n=16 ; \text { FBT } \\
n=23\end{array}$ & $\begin{array}{l}\text { CBT-E lower weight: } \\
\text { \% median BMI=94.4 } \\
\text { Significant } \\
\text { improvement in } \\
\text { eating-disorder } \\
\text { and general } \\
\text { psychopathology } \\
\text { CBT-E higher weight: } \\
\text { \% median BMI= } \\
108.3 \\
\text { Significant } \\
\text { improvement in } \\
\text { eating-disorder } \\
\text { and general } \\
\text { psychopathology } \\
\text { FBT lower weight: } \\
\text { \% median BMl= } 96.8 \\
\text { Significant } \\
\text { improvement in } \\
\text { eating-disorder } \\
\text { and general } \\
\text { psychopathology } \\
\text { FBT higher weight: } \\
\text { \% median BMl= } 112.6 \\
\text { Significant } \\
\text { improvement in } \\
\text { eating-disorder } \\
\text { and general } \\
\text { psychopathology. }\end{array}$ & $\begin{array}{l}\text { CBT-E lower weight: } \\
\% \text { median BMI=96.4 } \\
\text { Significant } \\
\text { improvement in } \\
\text { eating-disorder } \\
\text { and general } \\
\text { psychopathology } \\
\text { CBT-E higher weight: } \\
\% \text { median BMI= } 107.2 \\
\text { Significant } \\
\text { improvement in } \\
\text { eating-disorder } \\
\text { and general } \\
\text { psychopathology } \\
\text { FBT lower weight: } \\
\% \text { median BMI= } 96.2 \\
\text { Significant } \\
\text { improvement in } \\
\text { eating-disorder } \\
\text { and general } \\
\text { psychopathology } \\
\text { FBT higher weight: } \\
\% \text { median BMI= } 111.5 \\
\text { Significant } \\
\text { improvement in } \\
\text { eating-disorder } \\
\text { and general } \\
\text { psychopathology }\end{array}$ \\
\hline
\end{tabular}

$\mathrm{BMI}=$ Body mass index; ITT=intention-to-treat; SD=standard deviation; SE=standard error; lower weight= $<90 \%$ median body mass index; higher weight $=\geq 90 \%$ median body mass index.

* Minimal residual eating-disorder psychopathology=Eating Disorder Examination Questionnaire global score < 1SD above the community mean (i.e., <2.77); ${ }^{\circledR} \mathrm{BMI} \geq 18.5 \mathrm{~kg} / \mathrm{m}^{2}$ and Eating Disorder Examination Questionnaire global score $<1 \mathrm{SD}$ above the community mean (i.e., <2.77). ${ }^{* *}$ Minimal residual eating-disorder psychopathology= Eating Disorder Examination global score $<1 S D$ above the community mean (i.e., <1.74) 
were excluded because they included only adult patients and a further two for using a generic form of CBT. Finally, three papers only showed outcome data for adolescent and adult patients combined (Figure 1). Thus, at the end of the screening process, eight papers were considered suitable for systematic review and narrative synthesis. According to the NICE guideline checklist, the quality of selected studies ranged from fair to good (mean score 5.87 points) (Table 2).

In 2013, Dalle Grave et al. (2013) evaluated the effectiveness of outpatient CBT-E in a cohort of 49 adolescent patients with anorexia nervosa consecutively referred to an eating disorder clinic. Only three patients (6.1\%) declined to start CBT-E, and among the 46 who accepted the treatment, 29 (63\%) completed it, and all of these participated in 60 weeks of follow-up. Intention-to-treat analysis $(\mathrm{n}=46)$ showed that the mean BMI-for-age percentile significantly increased from $2.86(\mathrm{SD}=3.35)$ at baseline to $19.8(\mathrm{SD}=19.2)$ at end of treatment and to $23.6(\mathrm{SD}=25.7)$ at 60 -week follow-up. Moreover, $21.7 \%$ and $28.3 \%$ of patients gained sufficient weight from baseline to achieve
$95 \%$ of their expected weight at the end of treatment and follow-up, respectively. Eating-disorder psychopathology (measured using the EDE-Q global score) decreased from $2.79(\mathrm{SD}=1.5)$ at baseline to $1.50(\mathrm{SD}=1.5)$ at the end treatment and $1.51(\mathrm{SD}=1.6)$ at follow-up. Furthermore, $79.1 \%$ and $76.7 \%$ reached a global EDE-Q $<1 S D$ above the community mean at the end of treatment and follow-up, respectively. General psychiatric features also decreased significantly from baseline to the end of treatment and follow-up. As expected, results were better in the 29 patients who completed the treatment.

In 2014, Dalle Grave et al. (2014) evaluated the effectiveness of inpatient CBT-E in a sample of adolescents with anorexia nervosa at the end of treatment and at 6- and 12-month follow-up. Thirty-two patients were eligible and 27 agreed to participate in the study. All 27 patients except one completed the treatment, and 22 and 23, respectively, participated in the follow-up interviews conducted 6 and 12 months after discharge. Intention-to-treat analysis indicated a significant increase in BMI percentile from baseline

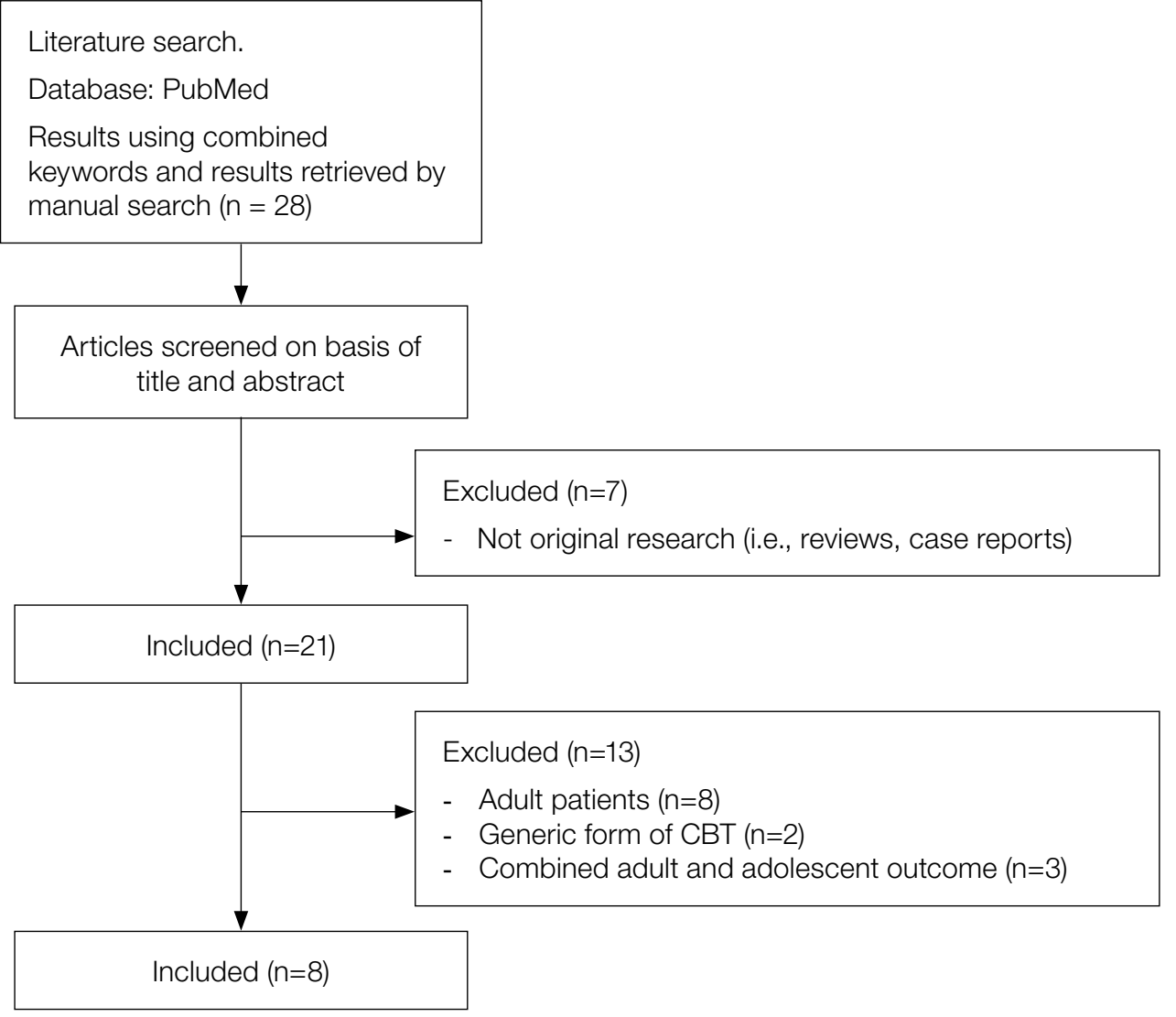

Figure 1. Flow chart summarizing the study selection procedure 
Table 2. Evaluation of methodological quality of studies assessing cognitive behavioural therapy for eating disorders in adolescents with anorexia nervosa

\begin{tabular}{|c|c|c|c|c|c|c|c|c|}
\hline & $\begin{array}{c}\text { Dalle Grave } \\
\text { et al. } \\
\text { (2013) }\end{array}$ & $\begin{array}{c}\text { Dalle Grave } \\
\text { et al. } \\
\text { (2014) }\end{array}$ & \begin{tabular}{|c|} 
Dalle Grave \\
et al. \\
$(2015)$
\end{tabular} & $\begin{array}{l}\text { Calugi } \\
\text { et al. } \\
(2015)\end{array}$ & \begin{tabular}{|c|} 
Calugi \& \\
Dalle Grave \\
(2019)
\end{tabular} & \begin{tabular}{|c|} 
Dalle Grave \\
et al. \\
(2019)
\end{tabular} & \begin{tabular}{|c|} 
Dalle Grave \\
et al. \\
$(2020)$
\end{tabular} & $\begin{array}{c}\text { Le Grange } \\
\text { et al. } \\
\text { (2020) }\end{array}$ \\
\hline $\begin{array}{l}\text { Case series collected in more than one } \\
\text { centre, i.e., multicentric study }\end{array}$ & 0 & 0 & 0 & 0 & 0 & 0 & 0 & 0 \\
\hline $\begin{array}{l}\text { Is the hypothesis/aim/objective of the } \\
\text { study clearly described? }\end{array}$ & 1 & 1 & 1 & 1 & 1 & 1 & 1 & 1 \\
\hline $\begin{array}{l}\text { Are the inclusion and exclusion criteria } \\
\text { (case definition) clearly reported? }\end{array}$ & 1 & 1 & 1 & 1 & 1 & 1 & 1 & 1 \\
\hline $\begin{array}{l}\text { Is there a clear definition of the } \\
\text { outcomes reported? }\end{array}$ & 0 & 1 & 0 & 1 & 1 & 1 & 1 & 1 \\
\hline Were data collected prospectively? & 1 & 1 & 1 & 1 & 1 & 1 & 1 & 1 \\
\hline $\begin{array}{l}\text { Is there an explicit statement that } \\
\text { patients were recruited consecutively? }\end{array}$ & 1 & 1 & 1 & 1 & 1 & 1 & 1 & 1 \\
\hline $\begin{array}{l}\text { Are the main findings of the study } \\
\text { clearly described? }\end{array}$ & 1 & 1 & 1 & 1 & 1 & 1 & 1 & 1 \\
\hline $\begin{array}{l}\text { Are outcomes stratified? (e.g., by } \\
\text { disease stage, abnormal test results, } \\
\text { patient characteristics) }\end{array}$ & 0 & 0 & 0 & 0 & 0 & 0 & 0 & 1 \\
\hline Total score & 5 & 6 & 5 & 6 & 6 & 6 & 6 & 7 \\
\hline
\end{tabular}

NICE guidelines checklist; a total score of 0-3 indicates poor quality; between 4 and 6 fair quality; and $\geq 7$ good quality.

to end of treatment, from $2.7(\mathrm{SD}=4.3)$ to $34.2(\mathrm{SD}=15.7)$; at 6- and 12-month follow-ups, the BMI percentile was $27.3(\mathrm{SD}=20.8)$ and $29.9(\mathrm{SD}=20.1)$, respectively. Completer analysis indicated similar results, specifically a BMI percentile of $35.5(\mathrm{SD}=14.5)$ at end of treatment and 25.4 $(\mathrm{SD}=20.6)$ and $29.5(\mathrm{SD}=19.6)$ at 6 - and 12-month follow-ups, respectively. Among completers, $96.2 \%$ achieved a BMI percentile corresponding to $\mathrm{BMI} \geq 18.5$ at the end of treatment, and $82.6 \%$ had a BMI equivalent to $\geq 18.5$ at 12-month follow-up. Eating-disorder psychopathology was significantly decreased, with $38.5 \%, 59.1 \%$ and $60.9 \%$ showing minimal eating-disorder psychopathology (i.e., global $\mathrm{EDE}<1 \mathrm{SD}$ above the community mean) at the end of treatment and the two follow-ups, respectively.

One-year later, Calugi et al. (2015) studied the same sample of adolescents with anorexia nervosa and compared the duration of treatment required to restore body weight with that of a sample of adults with anorexia nervosa. Two BMI thresholds were selected: $\geq 18.5$ and $\geq 19.5$ in those of 18 years and over, or the corresponding BMI-for-age percentile in those under 18. Among the adolescent sample, $65.3 \%$ reached a BMI $\geq 18.5$ or the corresponding BMI-forage percentile in an estimated mean time of 14.8 days of treatment, whereas only $36.5 \%$ of the adult sample reached this cut-off ( $\mathrm{p}=0.003)$ in an estimated time of 28.3 days $(\mathrm{p}<0.001)$. Moreover, $55.1 \%$ of adolescents and $32.6 \%$ of adults $(\mathrm{p}=0.047)$ reached a $\mathrm{BMI} \geq 19.5$ or the corresponding BMI-for-age percentile in an estimated mean time of 25.1 days for adolescents and of 36.4 days for adults $(\mathrm{p}<0.001)$.

In the same year, Dalle Grave et al (2015) published the first study assessing CBT-E in not-underweight adolescent outpatients. The sample comprised 68 not-underweight patients, $20(29.4 \%)$ with bulimia nervosa, $14(20.6 \%)$ with binge-eating disorder, and $34(50.0 \%)$ with another presentation of eating disorder. Data were collected at baseline and end of treatment. Intention-to-treat analysis indicated significant improvements in eating-disorder and general psychopathology. Moreover, the frequency of binge eating, self-induced vomiting and laxative misuse decreased substantially, and half of those who were binge eating or purging at the beginning of treatment had ceased these behaviours altogether by the end of treatment. Furthermore, among completers, $82.4 \%$ met the criterion for having minimal residual eating-disorder psychopathology (i.e., global EDE-Q score below $1 \mathrm{SD}$ above the community mean, 2.77), and of those who were binge eating or purging at the beginning of treatment, $76.5 \%$ had completely ceased these behaviours by the end. 
In 2019, Calugi \& Dalle Grave (2019) evaluated the influence of baseline measures of body-image concern on changes in BMI-for-age percentile and psychopathological outcomes associated with intensive CBT-E in 62 adolescents with anorexia nervosa for 12 months after discharge The mean starting age of participants was 16.4 years $(\mathrm{SD}=1.2)$, the mean baseline BMI-for-age percentile $1.8(\mathrm{SD}=3.5)$, and the mean body weight $39.1 \mathrm{~kg}(\mathrm{SD}=5.6)$. Fifty-six patients $(90.3 \%)$ completed the treatment and $47(83.9 \%)$ and $46(86.7 \%)$ patients participated in the follow-up interviews held 6 and 12 months after discharge, respectively. Considering treatment outcome as the percentage of patients who reached a BMI-for-age percentile corresponding to a normal weight cut-off (i.e., $18.5 \mathrm{~kg} / \mathrm{m}^{2}$ ) at 18 years of age, authors found that $96.4 \%$ of completers at end of treatment and $78.7 \%$ and $80.4 \%$ at 6 - and 12 -month follow-up, respectively, reached this cut-off. Moreover, eating-disorder and general psychopathology scores decreased significantly from baseline to end of treatment and remained stable at follow-ups both in completers and at intention-to-treat analysis.

In the same year, Dalle Grave et al. (2019) published a study aiming to establish the outcomes and predictors of change in a cohort of adolescents with anorexia nervosa treated via outpatient CBT-E in a real-world clinical setting. Authors assessed 99 patients for eligibility, and enrolled 49 patients in the study. Of the 50 patients excluded, 30 did not meet the inclusion criteria, 18 met the exclusion criteria, and only two declined to participate. At baseline, the 49 adolescents had a mean age of 15.5 years $(\mathrm{SD}=1.7)$, mean BMIfor-age percentile of 5.67 ( $\mathrm{SD}=7.30$, range $0.5-23.5$, median 1.4 ), and mean duration of illness of 0.95 years (range $0-4$, median 1 year). Thirty-five patients $(71.4 \%)$ completed the full 40 sessions of CBT-E, and 29 (82.9\%) of these participated in the follow-up interview at 20 weeks. Findings indicated a significant increase in BMI-for-age percentile over the course of treatment, and a subsequent deceleration in this improvement during follow-up. Eating-disorder and general psychopathology and clinical impairment scores significantly decreased over treatment, and continued to improve, albeit more slowly, up to 20-week follow-up. Among the 35 patients who completed the treatment, $22(62.9 \%)$ had a BMI-for-age percentile corresponding to an adult BMI of $\geq 18.5 \mathrm{~kg} / \mathrm{m}^{2}$ plus a global EDE-Q score of less than $1 \mathrm{SD}$ above the community mean, i.e., $<2.77$, at the end of treatment. This outcome was reached in $48.3 \%(n=14)$ of the 29 adolescent patients who completed the 20-week follow-up.

In light of data from the previous study by Calugi et al. (2015) suggesting that CBT-E might be even more ef- fective in adolescents, Dalle Grave et al (2020) assessed the respective efficacy of intensive CBT-E in adolescents and adults with anorexia nervosa. One-hundred and sixty-one adolescents were assessed for eligibility, but 58 did not meet the inclusion criteria; 3 met the exclusion criteria and 26 declined to participate, meaning that, overall, 74 consecutive adolescent patients were included in the study and participated in a 20-week intensive CBT-E programme. Among the 192 adults assessed for eligibility, $68 \mathrm{did}$ not meet the inclusion criteria, 1 met the exclusion criteria, and 42 declined to participate, leaving a total of 81 adult patients. Data collected at the end of treatment and at 20and 60-week follow-ups revealed no differences between adolescents and adults at any time point. Intention-to-treat analysis indicated that, among adolescents, BMI-for-age percentile showed an initial significant increase over treatment and a subsequent deceleration in the rate of change during follow-up, with similar results being found in the adult sample. Eating-disorder and general psychopathology and clinical impairment scores also significantly improved from baseline to 60-week follow-up in both groups. Results were also similar in terms of 'good BMI outcome' $(B M I \geq 18.5)$, which was achieved by $93.7 \%(n=59)$ of adolescent and $87.3 \%(n=62)$ of adult completers, and 'full response' (BMI $\geq 18.5$ and EDE-Q global score of $<2.77$ ), which was achieved by $76.2 \%(\mathrm{n}=48)$ of adolescents and $70.4 \%(n=50)$ of adults at the end of treatment. At 20 -week follow-up 'good BMI outcome' was seen in $82.6 \%(\mathrm{n}=38)$ of adolescents and $71.7 \%(n=38)$ of adults, while at 60 week follow up it was seen in $62.2 \%(\mathrm{n}=28)$ of adolescents and $66.7 \%(\mathrm{n}=24)$ of adults. Thirty-three adolescents $(71.7 \%)$ and 35 adults (66.0\%) were classed as 'full responders' at 20-week follow-up, while 22 adolescents (48.9\%) and 20 adults (55.6\%) still showed a 'full response' at 60week follow-up.

The study most recently published on this topic, by Le Grange et al. (2020), reports on a non-randomized trial comparing the relative effectiveness of family-based treatment and CBT-E in adolescents. The sample was divided into lower weight $[<90 \%$ median BMI (mBMI)], and higher weight cohorts ( $\geq 90 \% \mathrm{mBMI}$ ). Among 107 eligible patients, 97 were enrolled, and 51 (52.5\%) participants/families chose FBT, while 46 (47.5\%) chose CBT-E. In the FBT arm, $33(64.7 \%)$ completed the treatment, 20 (39.1\%) of whom were assessed at 6-month follow-up and $23(45.1 \%)$ at 12 -month follow-up, as compared to $29(63 \%)$ completers and $22(47.8 \%)$ and $16(34.8 \%)$ assessed at 6 months and 12 months, respectively in the CBT-E arm. The mean age of the entire sample was 14.6 years $(\mathrm{SD}=1.8$, range 
11-19) and the mean duration of illness was 17.0 months $(\mathrm{SD}=18.3$, range 1-84). In the lower weight cohort, the mean percentage mBMI $(\mathrm{n}=37)$ was $83.6 \%(\mathrm{SD}=4.1$, median $=83.4$, range $=74.8-89.8$ ), while it was 103.7 (S.D. $=$ 11.9 , median $=101.21$, range $=90.3-142.1)$ in the higher weight cohort. In both cohorts (lower weight and higher weight), weight gain was significantly higher at the end of FBT as compared to CBT-E, but at 6- and 12-month follow-ups the two treatments were comparable in terms of weight gain. No differences in eating-disorder or general psychopathology or clinical impairment scores were found between FBT and CBT-E at any time point.

\section{Discussion}

\section{Summary of Findings}

The current systematic review supports the effectiveness of CBT-E as a promising treatment for adolescents with eating disorders. Two clinical series (Dalle Grave et al., 2013; Dalle Grave, Sartirana, et al., 2019) assessing the effectiveness of outpatient CBT-E for adolescents with anorexia nervosa found that the treatment is well accepted and completed by about two-thirds of adolescent patients. The treatment was associated with a significant increase in BMI-for-age percentile and significant improvements in eating-disorder and general psychopathology scores. These improvements were maintained at 20- and 60-week follow-ups. Among completers, about $50 \%$ of patients had achieved complete remission from anorexia nervosa at follow-up.

CBT-E seems to more effective for adolescents than adults with anorexia nervosa. The only study to compare the effectiveness of CBT-E in these groups found that a significantly higher percentage of adolescents than adults achieved normal weight at the end of the treatment $(65.3 \%$ and $36.5 \%$, respectively). Adolescents also required a shorter estimated mean time to achieve normal weight (Calugi et al., 2015).

CBT-E seems particularly effective when is delivered to adolescents with anorexia nervosa in an inpatient setting, generally used to treat the most severe and medically unstable patients. Indeed, all three case series (Dalle Grave et al., 2014; Dalle Grave, Conti, et al., 2020; Dalle Grave, Sartirana, et al., 2019) assessing the effectiveness of inpatient CBT-E found that the treatment is well accepted and completed by about $90 \%$ of such patients. Like outpatient CBT-E, inpatient CBT-E is associated with a significant increase in BMI-for age percentile and significant improvements in eating-disorder and general psychopathology scores, which appear to be maintained at follow-up. Even in this group of severely ill patients, $80 \%$ had reached normal weight and roughly $50 \%$ complete remission of anorexia nervosa at one year. Unlike that observed with outpatient CBT-E (Calugi et al., 2015), however, adolescents and adults with anorexia nervosa treated with inpatient CBT-E showed similar outcomes at both the end of treatment and follow-up (Dalle Grave, Conti, et al., 2020).

The data on the effectiveness of CBT-E for not-underweight adolescent outpatients is limited. However, one study assessing the effectiveness of outpatient CBT-E in not-underweight adolescent patients with bulimia nervosa, binge-eating disorder or other eating disorders showed that about three-quarters completed the treatment, and about half of those who were binge eating or purging at the beginning of treatment had ceased these behaviours by the end of treatment (Dalle Grave et al., 2015). Among completers, more than $80 \%$ had minimal residual eating-disorder psychopathology at the end of treatment. Unfortunately, no follow-up data is available.

Only one study has thus far compared CBT-E for adolescents with eating disorders with another form of treatment. That study was a non-randomized trial comparing the relative effectiveness of CBT-E and FBT in adolescents, who were assigned to treatment groups on the basis of preference and divided into a lower weight cohort and a higher weight cohort (Le Grange et al., 2020). FBT was more effective than CBT-E in terms of weight gain (measured on a slope) from baseline to the end of treatment. However, there were no appreciable differences between the two treatments at either 6- or 12-month follow-ups. Moreover, no difference was found between FBT and CBT-E in terms of eating-disorder and general psychopathology or clinical impairment scores at any time points. The slower initial weight gains achieved by CBT-E recipients as compared to FBT may be ascribable to the strategies used by the two treatments to achieve weight gain. In fact, in CBT-E weight gain (when indicated) is not addressed until 4 weeks into the treatment, and only when patients conclude that they need to tackle their low weight. In contrast, weight gain (when indicated) is addressed by FBT at the outset, driven by parental support and encouragement. An interesting piece of information to emerge from this study was that older and less well participants opted for CBT-E rather than FBT. This led the authors to speculate that parents seem to consider individual rather than family-based therapy to be more appropriate when their offspring are older and more unwell.

This systematic review of eight studies supports the effectiveness of CBT-E for adolescents with anorexia ner- 
vosa. The treatment is well accepted by adolescent patients and their parents and yields promising results both in terms of weight gain and improvements in eating-disorder and general psychology, with about half of the patients achieving full remission from anorexia nervosa 12 months after completing the treatment. These results give further support to the NICE guidelines recommending CBT-E for eating disorders as the most valid alternative to FBT when the latter is unacceptable, contraindicated, or ineffective (National Guideline Alliance, 2017). CBT-E in an inpatient setting also seems particularly promising for adolescents with anorexia nervosa who are admitted due to their severe medical and/or mental conditions or lack of response to outpatient treatments. More studies are, however, necessary before drawing any conclusions about the effectiveness of CBT-E for not-underweight adolescent patients with eating disorders.

\section{Summary of Limitations}

These findings should be interpreted with caution, bearing in mind the following limitations. First and foremost, all the eight studies included in the review had a non-controlled design. They are therefore unable to meaningfully assess whether CBT-E for adolescent patients with anorexia nervosa and other eating disorders is more effective than other available treatments or no treatment. Although CBT-E yielded similar outcomes to FBT in the only non-randomized effectiveness trial that compared the two (Le Grange et al., 2020), the relative efficacy of CBT-E in comparison with FBT remains an empirical question that should be assessed in future randomized controlled trials. Second, although several studies had a follow-up of about 12 months (Calugi \& Dalle Grave, 2019; Dalle Grave et al., 2013; Dalle Grave et al., 2014; Dalle Grave, Conti, et al., 2020; Dalle Grave, Sartirana, et al., 2019), data from a longer follow-up period would be necessary to determine the stability of changes in the long term. Third, the number of studies was relatively small for many of the comparisons and subgroup analyses to suggest robust conclusions. Fourth, with the exclusion of the Le Grange et al. (2020) study, the other studies included in the review were performed by a single eating-disorder clinical service operating in a real-world setting, which was also involved in the development of CBT-E for adolescents. Larger multi-site studies will be needed to confirm that the effects of CBT-E for adolescents are replicable.

\section{Conclusions and Areas for Future Research}

The results of this systematic review suggest that CBT-E is a promising treatment for adolescents with an eating disorder, and there is now a compelling and urgent case for comparing CBT-E and FBT in randomized controlled trials. Variables of interests would be the acceptability of the two treatments, their efficacy, and their ability to produce lasting change and remission. It will be also important to evaluate the relative cost-effectiveness of the two treatments. Moreover, it would be of theoretical interest and practical importance to assess whether there are moderators of treatment outcome that might allow the matching of patients to CBT-E or FBT. This is not implausible, given that CBT-E and FBT are based on different conceptualizations, different levels of parental involvement, different strategies and procedures adopted to produce the change, and different postulated mechanisms of their action (Dalle Grave, Eckhardt, et al., 2019). The nature of the two treatments suggests that FBT might be more appropriate for younger adolescents, while CBT-E, being designed to address the cognitive and behavioural processes maintaining the eating-disorder psychopathology, might be more useful for older adolescents able to 'take charge' of these processes (Dalle Grave \& Calugi, 2020). This supposition is indirectly supported by findings from the only non-randomized effectiveness trial comparing FBT and CBT-E to date, in which the older, less well patients (or their parents) chose CBT-E, but this too remains to be confirmed.

\section{Footnotes}

Conflict-of-interest statement: Dalle Grave R and Calugi $S$ receive royalties from a book published by Guilford Press describing enhanced cognitive behavioral therapy for eating disorders.

\section{References}

American Psychiatric Association. (2013). Diagnostic and statistical manual of mental disorders, (DSM-5). Arlington: American Psychiatric Publishing.

Calugi, S., \& Dalle Grave, R. (2019). Body image concern and treatment outcomes in adolescents with anorexia nervosa. International Journal of Eating Disorders, 52(5), 582-585. doi:10.1002/eat.23031

Calugi, S., Dalle Grave, R., Sartirana, M., \& Fairburn, C. G. (2015). Time to restore body weight in adults and adolescents receiving cognitive behaviour therapy for anorexia nervosa. Journal of Eating Disorders, 3, 21. doi:10.1186/s40337-015-0057-z

Dalle Grave, R. (2012). Intensive cognitive behavior therapy for eating disorders. Hauppauge, NY: Nova.

Dalle Grave, R., Bohn, K., Hawker, D., \& Fairburn, C. G. (2008). Inpatient, day patient and two forms of outpatient CBT-E. 
In C. G. Fairburn (Ed.), Cognitive behavior therapy and eating disorders (pp. 231-244). New York: Guilford Press.

Dalle Grave, R., \& Calugi, S. (2020). Cognitive behavior therapy for adolescents with eating disorders. New York: Guilford Press.

Dalle Grave, R., Calugi, S., Doll, H. A., \& Fairburn, C. G. (2013). Enhanced cognitive behaviour therapy for adolescents with anorexia nervosa: an alternative to family therapy? Behaviour Research and Therapy, 51(1), R9-R12. doi:10.1016/j.brat.2012.09.008

Dalle Grave, R., Calugi, S., El Ghoch, M., Conti, M., \& Fairburn, C. G. (2014). Inpatient cognitive behavior therapy for adolescents with anorexia nervosa: Immediate and longerterm effects. Frontiers in Psychiatry, 5, 14. doi:10.3389/ fpsyt.2014.00014

Dalle Grave, R., Calugi, S., Sartirana, M., \& Fairburn, C. G. (2015). Transdiagnostic cognitive behaviour therapy for adolescents with an eating disorder who are not underweight. Behaviour Research and Therapy, 73, 79-82. doi:10.1016/j.brat.2015.07.014

Dalle Grave, R., Conti, M., \& Calugi, S. (2020). Effectiveness of intensive cognitive behavioral therapy in adolescents and adults with anorexia nervosa. International Journal of Eating Disorders. doi:10.1002/eat.23337

Dalle Grave, R., Eckhardt, S., Calugi, S., \& Le Grange, D. (2019). A conceptual comparison of family-based treatment and enhanced cognitive behavior therapy in the treatment of adolescents with eating disorders. Journal of Eating Disorders, 7(1), 42. doi:10.1186/s40337-019-0275-x

Dalle Grave, R., Sartirana, M., \& Calugi, S. (2019). Enhanced cognitive behavioral therapy for adolescents with anorexia nervosa: Outcomes and predictors of change in a real-world setting. International Journal of Eating Disorders, 52(9), 1042-1046. doi:10.1002/eat.23122

Dalle Grave, R., Sartirana, M., Sermattei, S., \& Calugi, S. (2020). Treatment of eating disorders in adults versus adolescents: Similarities and differences. Clinical Therapeutics. doi:10.1016/j.clinthera.2020.10.015

Flynn, M., Austin, A., Lang, K., Allen, K., Bassi, R., Brady, G., . . Schmidt, U. (2020). Assessing the impact of First Episode Rapid Early Intervention for Eating Disorders on duration of untreated eating disorder: A multi-centre quasiexperimental study. European Eating Disorders Review. doi:10.1002/erv.2797

Le Grange, D., Crosby, R. D., Rathouz, P. J., \& Leventhal, B. L. (2007). A randomized controlled comparison of family-based treatment and supportive psychotherapy for adolescent bulimia nervosa. Archives of General Psychiatry, 64(9), 1049-1056. doi:10.1001/archpsyc.64.9.1049

Le Grange, D., Eckhardt, S., Dalle Grave, R., Crosby, R. D., Peterson, C. B., Keery, H., . . . Martell, C. (2020). Enhanced cognitive-behavior therapy and family-based treatment for adolescents with an eating disorder: a non-randomized effectiveness trial. Psychological Medicine, 1-11. doi:10.1017/ s0033291720004407

Le Grange, D., Hughes, E. K., Court, A., Yeo, M., Crosby, R. D., \& Sawyer, S. M. (2016). Randomized clinical trial of parent-focused treatment and family-based treatment for adolescent anorexia nervosa. Journal of the American Academy of Child and Adolescent Psychiatry, 55(8), 683692. doi:10.1016/j.jaac.2016.05.007

Le Grange, D., Lock, J., Agras, W. S., Bryson, S. W., \& Jo, B. (2015). Randomized clinical trial of family-based treatment and cognitive-behavioral therapy for adolescent bulimia nervosa. Journal of the American Academy of Child and Adolescent Psychiatry, 54(11), 886-894.e882. doi:10.1016/j. jaac.2015.08.008

Liberati, A., Altman, D. G., Tetzlaff, J., Mulrow, C., Gotzsche, P.C., Ioannidis, J. P., ... Moher, D. (2009). The PRISMA statement for reporting systematic reviews and meta-analyses of studies that evaluate health care interventions: explanation and elaboration. Journal of Clinical Epidemiology, 62(10), e1-34. doi:10.1016/j.jclinepi.2009.06.006

Lock, J. (2011). Evaluation of family treatment models for eating disorders. Current Opinion in Psychiatry, 24(4), 274-279. doi:10.1097/YCO.0b013e328346f71e

Lock, J., \& Le Grange, D. (2013). Treatment manual for anorexia nervosa: A family-based approach (2nd ed.). New York: Guilford Press.

Lock, J., Le Grange, D., Agras, W. S., Moye, A., Bryson, S. W., \& Jo, B. (2010). Randomized clinical trial comparing family-based treatment with adolescent-focused individual therapy for adolescents with anorexia nervosa. Archives of General Psychiatry, 67(10), 1025-1032. doi:10.1001/ archgenpsychiatry.2010.128

National Guideline Alliance. (2017). Eating disorders: Recognition and treatment. London: National Institute for Health and Care Excellence (UK); 2017 May. (NICE Guideline, No. 69.) London.

National Institute for Health and Clinical Excellence. Clinical Guidelines, Appendix 4 Quality of Case Series Form. Retrieved from https://www.nice.org.uk/guidance/cg3/ documents/appendix-4-quality-of-case-series-form2

Popay, J., Roberts, H., Sowden, A., Petticrew, M., Britten, N., Arai, L., . . . Duffy, S. (2005). Developing guidance on the conduct of narrative synthesis in systematic reviews. Journal of Epidemiology and Community Health.

Richardson, W. S., Wilson, M. C., Nishikawa, J., \& Hayward, R. S. (1995). The well-built clinical question: a key to evidencebased decisions. ACP Journal Club, 123(3), A12-13. Retrieved from https://www.ncbi.nlm.nih.gov/pubmed/7582737

Swanson, S. A., Crow, S. J., Le Grange, D., Swendsen, J., \& Merikangas, K. R. (2011). Prevalence and correlates of eating disorders in adolescents. Results from the national comorbidity survey replication adolescent supplement. Archives of General Psychiatry, 68(7), 714-723. doi:10.1001/ archgenpsychiatry.2011.22

Wonderlich, S. A., Bulik, C. M., Schmidt, U., Steiger, H., \& Hoek, H. W. (2020). Severe and enduring anorexia nervosa: Update and observations about the current clinical reality. International Journal of Eating Disorders. doi:10.1002/ eat. 23283 